\title{
HPV16 E6 Promotes Breast Cancer Proliferation via Upregulation of COX-2 Expression
}

\author{
Y. X. Wang, ${ }^{1}$ Y. Z. Li, ${ }^{1}$ Z. Y. Zhang, ${ }^{1}$ J. Q. Wang, ${ }^{1,2}$ J. Cui, ${ }^{1}$ and X. L. Qian ${ }^{1}$ \\ ${ }^{1}$ Department of Pathology, School of Basic Medical Sciences, Xinxiang Medical University, Xinxiang 453003, China \\ ${ }^{2}$ The Third Affiliated Hospital of Xinxiang Medical University, Xinxiang 453003, China \\ Correspondence should be addressed to J. Cui; 13782518801@139.com and X. L. Qian; wangjiayi03@163.com
}

Received 6 April 2017; Revised 10 June 2017; Accepted 3 July 2017; Published 9 November 2017

Academic Editor: Myong Cheol Lim

Copyright (c) 2017 Y. X. Wang et al. This is an open access article distributed under the Creative Commons Attribution License, which permits unrestricted use, distribution, and reproduction in any medium, provided the original work is properly cited.

\begin{abstract}
Background. Breast cancer remains the leading cause of cancer-related mortality worldwide. It has been indicated that human papillomaviruses 16 (HPV16) might participate in the pathogenesis and development of breast cancer. However, the detected rate of HPV16 varies with region. We will investigate HPV16 E6 expression in North China and explore the effects and mechanism of HPV16 E6 on breast cancer proliferation in this study. Methods. The expressions of HPV16 E6 and COX-2 in paraffin-embedded tissues of the invasive ductal breast cancer were detected by qPCR and IHC. The effects of HPV16 E6 on breast cancer proliferation were determined by function studies. The mechanism of HPV16 E6 in promoting breast cancer proliferation was explored by Western blot and Dual-Luciferase Reporter Assay. Results. HPV16 E6 was positive in 28\% invasive ductal breast carcinoma in North China; HPV16 E6 promoted breast cancer proliferation. Inhibition of COX-2 by siCOX-2 or Celecoxib attenuated the proliferation of breast cancer cells with HPV16 E6 expression; and the upregulation of COX-2 could be suppressed by the inhibition of NF$\kappa \mathrm{B}$ activity. Conclusion. HPV16 E6 promotes breast cancer proliferation by activation of NF- $\kappa \mathrm{B}$ signaling pathway and increase of COX-2 expression. COX-2 will be a potential target for HPV16 E6-associated breast cancer.
\end{abstract}

\section{Introduction}

Breast cancer claims most deaths of women suffering from cancer worldwide; the incidence of breast cancer and mortality of cases with carcinoma has increased gradually in recent years $[1,2]$. It has been proven that the incidence of human breast cancer is related to such factors as lifestyle, medical conditions, oncogenic genes, and virus infection [38]. Human papillomaviruses (HPVs) are small DNA viruses with high affinity for epithelia. HPVs are classified into low risk (LR) and high risk (HR) according to their pathogenicity. Among the HPV genotype of high risk, HPV16 is the most prevalent. The integration of HPV16 DNA promotes a constitutive high expression of E6 oncoproteins and results in the extensive proliferation of the infected epithelial cells. Recently, HR-HPVs, especially HPV16, has been indicated to be involved in the pathogenesis and development of breast cancer. However, the detection rate varies with regions $[9,10]$. Some prophylactic vaccines to prevent the cancer by HPV16 have been developed [11]. Unfortunately, their effects are still unsatisfactory to most of the cases infected with HPV.

Cyclooxygenase-2 (COX-2) is an important isoform of COX which functions as catalyzer in the synthesis of prostaglandins (PG) from arachidonic acid [12]. COX-2 is undetectable in most normal tissues but is upregulated in many malignancies, including breast cancer [13]. A strong correlation between COX-2 and carcinogenesis has been confirmed by carcinogen-induced animal models in recent studies, which indicates that COX-2 plays an important role in tumor promotion. COX-2 can promote the proliferation, angiogenesis, invasiveness, metastasis and inhibition of apoptosis, and immunosurveillance [14]. Celecoxib is a selective COX-2 inhibitor, and it can also be used to treat cancers of some kinds [15-17]. Although COX-2 is overexpressed in HPV-induced lesions, it is still uncertain whether the upregulation of COX-2 results from HPV16 E6 in breast cancer. 
In this study, the expression and relationship of HPV16 E6 and COX2 DNA in paraffin-embedded invasive ductal breast cancer in the north of China will be explored and whether COX-2 is the target of HPV16 E6 or not will be made clear. Therefore, this study is important to the improvement of carcinogenic mechanism of HPV16 E6 and exploration of new therapeutic target for HPV16 E6-associated cancers.

\section{Materials and Methods}

2.1. Tissue Specimens. 50 cases of invasive ductal breast cancer samples were collected from Department of Pathology, the Third Affiliated Hospital of Xinxiang Medical University (Xinxiang, China), from January 2010 to December 2011. All the cases were female and had no chemotherapy, radiotherapy, and immunotherapy history. The patients are in the $25-85$ age bracket $(55.5 \pm 14.4)$. All the samples were fixed in buffered formalin, embedded in paraffin, and stored at room temperature for later use. And the samples had been diagnosed with invasive ductal breast cancer by two pathologists on the basis of Hematoxylin-Eosin (HE) staining sections. This study was approved by the ethics committee of Xinxiang Medical University Institutional Board (Xinxiang, China).

2.2. DNA Isolation and $q P C R$. 10 pieces of $4 \mu \mathrm{m}$ paraffin sections were collected from each sample for DNA isolation. During cutting, the first 3 sections and the excess paraffin were discarded, and the remainder was gathered in a $1.5 \mathrm{~mL}$ tube. DNA was extracted with QIAamp DNA FFPE Tissue Kit (QIAGEN, Germany) from the paraffin-embedded tissues according to the manufacturer's instruction. Firstly, the sections were disposed of with xylene for deparaffinization (3 $\times 10 \mathrm{~min}$ ) and then were rehydrated through graded ethanol steps. Next, the samples were dried at room temperature and later incubated overnight at $56^{\circ} \mathrm{C}$ with Proteinase K. On the next day, the samples were incubated for 1 hour at $90^{\circ} \mathrm{C}$ and then the mixture of AL Buffer and $100 \%$ ethanol was added. After brief spinning, the entire lysate was transferred to the QIAamp MinElute column, washed twice, and centrifuged (1400 rpm, $3 \mathrm{~min}$ ). Lastly, DNA was eluted from the column by ATE buffer. HPV16 E6 and COX-2 DNA were detected by qPCR by the Applied Biosystems 7500 Sequence Detection system, using SYBR Green I. The CT values above 35 were not acceptable. And the valid data were normalized to the geometric mean of housekeeping gene GAPDH and calculated as $2^{-\Delta \Delta C T}$. The primers for $\mathrm{qPCR}$ were shown in Table 1. The cycling conditions were as follows: initial denaturation for $1 \mathrm{~min}$ at $95^{\circ} \mathrm{C}, 45$ cycles of denaturation at $95^{\circ} \mathrm{C}$ for $30 \mathrm{sec}$, annealing at $50^{\circ} \mathrm{C}$ for $45 \mathrm{sec}$, extension at $72^{\circ} \mathrm{C}$ for $30 \mathrm{sec}$, and the last extension at $72^{\circ} \mathrm{C}$ for $5 \mathrm{~min}$.

2.3. Immunohistochemistry. The expressions of HPV16 E6 and COX-2 protein in breast invasive ductal carcinoma samples were detected by SP immunohistochemistry (SP9000, ZSGB-BIO, China). Paraffin-embedded specimens were firstly cut into $4 \mathrm{um}$ sections and baked at $60^{\circ} \mathrm{C}$ for 1 hour, deparaffinized with xylenes, and rehydrated with graded ethanol. After incubation in $3 \% \mathrm{H}_{2} \mathrm{O}_{2}$ to quench the endogenous peroxidase activity, the sections were heated in $0.01 \mathrm{M}, \mathrm{pH} 6.0$, sodium citrate buffer for antigenic retrieval. Later, the sections were blocked with normal nonimmune serum for $20 \mathrm{~min}$ and then incubated with rabbit anti-HPV16 E6 (1:50; Santa Cruz, USA) or rabbit anti-COX-2 (1:100; Proteintech, USA) overnight at $4^{\circ} \mathrm{C}$. At the next day, the sections were treated with universal type of secondary antibody and followed with streptavidin-horseradish peroxidase complex. Diaminobenzidine (DAB, ZSGB-BIO, China) was used for color development. PBS was used to replace primary antibody as negative contrast. Finally, the stained slides were evaluated independently by two pathologists who were blind to the clinical parameters. The positive tumor cells were stained in the nucleus for HPV16 E6 protein. The IHC staining of COX2 was done in the cytoplasm and assessed as high expression or low expression according to the IRS scores [18].

2.4. Cell Culture and Western Blot. The stable cells of MCF7/HPV16 E6 and MCF-7/Vector established in our previous study were cultured in DMEM (Invitrogen). The medium was supplemented with $10 \%$ fetal bovine serum (FBS, Gibco) and 1\% penicillin/streptomycin (Invitrogen). Protein lysates obtained from the cells were resolved on 10.5\% SDS polyacrylamide gel and electrotransferred to polyvinylidene difluoride (PVDF, Merck Millipore) membranes. Later, the PVDF membranes were treated with 5\% nonfat dry milk and then incubated with rabbit anti-HPV16 E6 (1:200; Santa Cruz, USA), rabbit anti-COX-2 (1:200; proteintech, USA), or mouse a-tubulin (1:2000; Cell Signaling Technology, USA) overnight at $4^{\circ} \mathrm{C}$. At last, the membranes were incubated with the appropriate secondary antibodies HRP-conjugated anti-rabbit IgG (1:5000, CST, USA) or HRP-conjugated anti-mouse IgG (1:5000, CST, USA) and detected by the chemiluminescence imaging analysis system (Tanon, China).

\subsection{MTT Assay, Colony Formation Assay, and Soft Agar Assay}

2.5.1. MTT Assay. $1 \times 10^{3}$ cells were seeded on 96-well plates and cultured for $24 \mathrm{~h} .20 \mu \mathrm{l} 5 \mathrm{~g} / \mathrm{l} 3$-(4,5-dimethylthiazol-z-yl)2,5-diphenyltetrazolium bromide (MTT, Sigma, USA) was added to each well and incubated for $4 \mathrm{~h}$. Then, MTT was removed and $150 \mu$ l dimethylsulfoxide (DMSO; Sigma, USA) was added to the wells. The absorbance was measured at $450 \mathrm{~nm}$ with a microplate autoreader (Bio-Rad, Hercules, CA, USA). The experiment was conducted repeatedly for three times.

2.5.2. Colony Formation Assay. Cells were trypsinized and plated on 6-well plates (200 cells/well) and cultured for 2 weeks. The colonies were stained with Hematoxylin for $30 \mathrm{~min}$ after fixation with $4 \%$ paraformaldehyde for $5 \mathrm{~min}$ utes. The number of colonies, defined as $>50$ cells/colony, was counted. Three independent experiments were performed.

2.5.3. Soft Agar Assay. Six-well plates were covered with a layer of $0.6 \%$ agar (Sigma, USA) in medium supplemented with $20 \%$ fetal bovine serum. Cells were prepared in $0.3 \%$ agar and seeded in triplicate at a dilution of $1 \times 10^{3}$. The plates were incubated at $37^{\circ} \mathrm{C}$ in a humid atmosphere of $5 \% \mathrm{CO}_{2}$ 
TABLE 1: Primer sequences used for qPCR.

\begin{tabular}{lrr}
\hline Gene & Forward primer & Reverse primer \\
\hline HPV16E6 & GTATGGAACAACATTAGAACAGCAA & GTGGCTTTTGACAGTTAATACACC \\
COX-2 & CGAGGTGTATGTATGAGTGT & AGTGGGTAAGTATGTAGTGC \\
GAPDH & GACTCATGACCACAGTCCATGC & AGAGGCAGGGATGATGTTCTG \\
\hline
\end{tabular}

for 2 weeks. Each experiment was repeated at least 3 times. Colonies were photographed after 2 weeks at an original magnification of $\times 200$.

2.6. Tumorigenesis in Nude Mice. 4-6-week-old BABL/c nude mice were purchased from the Center of Laboratory Animal Science of Guangdong (Guangzhou, China). All animal experiments were conducted in accordance with current Chinese regulations and standards regarding the use of laboratory animals, and all animal procedures were approved by the Xinxiang Medical University Institutional Animal Care and Use Committee. Xenograft tumors were generated by subcutaneous injection of $2 \times 10^{6}$ stable cells of MCF7/HPV16 E6 and MCF7/Vector $(n=6)$ on the hindlimbs. Tumor size was measured by a slide caliper twice weekly (volume $=$ length $\times$ width $\times$ height). All mice were euthanized 3 weeks later and the tumors were fixed and $4 \mu \mathrm{m}$ sections were cut and stained with Hematoxylin and Eosin according to standard protocols. Sections were further under IHC staining by antibody against Ki-67.

2.7. SiRNA, Celecoxib, and PDTC Treatment. COX-2 siRNA (the target sequence: GCTCAGCCATACAGCAAAT, Ribob Biotechnology, China) was transfected into the cells by Lipofectamine 2000 Reagent (Invitrogen). Or the cells were treated with Celecoxib (Selleck Chemicals) at a concentration of $1 \mathrm{~mol} / \mathrm{L}$ which had been diluted by dimethylsulfoxide (DMSO, Sigma) for $48 \mathrm{~h}$. Then the cells were used for protein collection or functional experiments. The cells were treated by the NF- $\kappa$ B inhibitor of pyrrolidinedithiocarbamate (PDTC, Beyotime Institute of Biotechnology) at a concentration of $0.5 \mathrm{~mol} / \mathrm{L}$ which had been diluted by DMSO for $48 \mathrm{~h}$ and then the cells were used for the following experiments.

2.8. Dual-Luciferase Reporter Assay. Cells at $60 \%$ confluence in 24-well plate were cotransfected with the NF- $\kappa$ B Luciferase Reporter (Beyotime Institute of Biotechnology, China), the Renilla Luciferase Reporter Vector pRL-TK (Promega), and the Vector or HPV16 E6 plasmids by lipofectamine 2000. 48 hours later, the Passive Lysis Buffer (PLB) was added to lyse and then was collected. Luciferase Assay Reagent II (LAR II) was added to measure the firefly luminescent signal. Then the reaction was quenched, and the Renilla Luminescence was detected immediately after adding Stop \& Glo Reagent. All of the experiments were conducted three times.

2.9. Statistical Analysis. All statistical analyses were performed by SPSS 20.0 for Windows. The data were expressed as means \pm standard deviations from at least three independent experiments. Student's $t$-test was conducted for the analysis of the two groups. The Spearman correlation was used to analyze the correlation between HPV16 E6 and COX-2 expression. $p<0.05$ was considered significant. Statistically significant data were indicated by asterisks: ${ }^{*}(p<0.05)$, ** $(p<0.01)$.

\section{Results}

3.1. Expression of HPV16 E6 DNA in Invasive Ductal Breast Cancer. The results of HPV16 E6 detection by qPCR in 50 cases of paraffin-embedded invasive ductal breast cancer samples showed that it was positive in 14 samples (28\%) (Table 2).

3.2. HPV16 E6 Promotes the Proliferation of Breast Cancer Cell In Vitro and In Vivo. We firstly examined the expression of HPV16 E6 protein in the stable cells of MCF-7/HPV16 E6 and MCF-7/Vector established in our previous study (Figure 1(a)). MTT assays revealed that the expression of HPV16 E6 significantly increased the growth of MCF-7 cells compared with the vector-transfected cells (Figure 1(b)). The results of colony formation assays and soft agar assays showed that the expression of HPV16 E6 significantly promoted the proliferation of MCF-7 cells in vitro (Figures $1(\mathrm{c})$ and 1(d)). The tumorigenesis assays in nude mice demonstrated that the tumors in the MCF7/HPV16 E6 group grew much faster than those in the MCF7/Vector group (Figure 1(e)). Furthermore, IHC confirmed that the tumors of the MCF7/HPV16 E6 group showed much higher Ki-67 index than that in MCF7/Vector group (Figure 1(f)).

3.3. HPV16 E6 Promotes the Proliferation of Breast Cancer by Upregulating COX-2 Expression. We examined the protein expression of COX-2 in MCF-7/HPV16 E6 and MCF$7 /$ Vector cells and found that the expression of COX-2 increased with the expression of HPV16 E6 (Figure 2(a)). Then, we treated MCF-7/HPV16 E6 cells with siCOX-2 and Celecoxib to suppress the expression of COX-2. A series of functional experiments were performed with these cells (Figure 2(b)). The results of MTT, colony formation, and soft agar assays showed that the suppression of COX-2 significantly inhibited the proliferation of MCF-7/HPV16 E6 cells (Figures 2(c)-2(e)). All of these results demonstrated that HPV16 E6 promoted breast cancer proliferation by upregulation COX-2 expression.

3.4. HPV16 E6 Expression Positively Correlates with COX2 Expression in Breast Cancer. We detected the expression of COX-2 DNA in the same 50 cases of paraffin-embedded invasive ductal breast cancer samples by qPCR and found that the expression level of COX-2 in HPV16 E6 positive samples was significantly higher than that in HPV16 E6 negative 
TABLE 2: HPV16 E6 and COX-2 DNA expression in invasive ductal breast cancer.

\begin{tabular}{|c|c|c|c|c|c|}
\hline Sample & Gender & Age & CT GAPDH $($ mean \pm SD) & CT of HPV16E6 $($ mean \pm SD) & CT of COX-2 (mean \pm SD) \\
\hline 1 & Female & 61 & $25.15 \pm 0.07$ & Undetermined & $27.56 \pm 0.43$ \\
\hline 2 & Female & 35 & $24.27 \pm 0.18$ & $26.26 \pm 0.09$ & $23.62 \pm 0.23$ \\
\hline 3 & Female & 39 & $25.51 \pm 0.32$ & Undetermined & $27.68 \pm 0.39$ \\
\hline 4 & Female & 59 & $23.55 \pm 0.18$ & $24.53 \pm 0.17$ & $21.38 \pm 0.38$ \\
\hline 5 & Female & 35 & $26.42 \pm 0.23$ & $26.54 \pm 0.29$ & $25.36 \pm 0.24$ \\
\hline 6 & Female & 73 & $26.09 \pm 0.32$ & Undetermined & $28.29 \pm 0.10$ \\
\hline 7 & Female & 50 & $28.07 \pm 0.07$ & Undetermined & $27.18 \pm 0.11$ \\
\hline 8 & Female & 64 & $24.58 \pm 0.20$ & $30.25 \pm 0.17$ & $23.22 \pm 0.19$ \\
\hline 9 & Female & 62 & $26.94 \pm 0.05$ & Undetermined & $29.52 \pm 0.18$ \\
\hline 10 & Female & 63 & $27.59 \pm 0.50$ & Undetermined & $25.67 \pm 0.34$ \\
\hline 11 & Female & 63 & $25.07 \pm 0.27$ & Undetermined & $27.77 \pm 0.35$ \\
\hline 12 & Female & 66 & $29.35 \pm 0.16$ & Undetermined & $28.77 \pm 0.44$ \\
\hline 13 & Female & 51 & $25.06 \pm 0.12$ & Undetermined & $27.53 \pm 0.41$ \\
\hline 14 & Female & 43 & $21.30 \pm 0.21$ & Undetermined & $26.64 \pm 0.91$ \\
\hline 15 & Female & 45 & $25.44 \pm 0.26$ & Undetermined & $27.56 \pm 0.29$ \\
\hline 16 & Female & 68 & $24.33 \pm 0.15$ & $35.77 \pm 0.12$ & $24.21 \pm 0.17$ \\
\hline 17 & Female & 74 & $26.49 \pm 0.30$ & Undetermined & $28.32 \pm 0.21$ \\
\hline 18 & Female & 42 & $26.28 \pm 0.19$ & $28.41 \pm 0.30$ & $24.42 \pm 0.15$ \\
\hline 19 & Female & 53 & $28.28 \pm 0.22$ & Undetermined & $27.30 \pm 0.10$ \\
\hline 20 & Female & 44 & $27.51 \pm 0.40$ & Undetermined & $28.52 \pm 0.18$ \\
\hline 21 & Female & 53 & $26.62 \pm 0.20$ & $32.35 \pm 0.21$ & $26.44 \pm 0.20$ \\
\hline 22 & Female & 41 & $27.60 \pm 0.50$ & Undetermined & $26.52 \pm 0.23$ \\
\hline 23 & Female & 59 & $24.57 \pm 0.23$ & Undetermined & $27.58 \pm 0.21$ \\
\hline 24 & Female & 42 & $29.44 \pm 0.23$ & Undetermined & $29.13 \pm 0.18$ \\
\hline 25 & Female & 44 & $25.67 \pm 0.17$ & Undetermined & $24.55 \pm 0.37$ \\
\hline 26 & Female & 33 & $24.67 \pm 0.20$ & $23.48 \pm 0.21$ & $22.33 \pm 0.17$ \\
\hline 27 & Female & 71 & $27.36 \pm 0.15$ & Undetermined & $27.52 \pm 0.37$ \\
\hline 28 & Female & 60 & $25.19 \pm 0.13$ & $29.36 \pm 0.15$ & $24.12 \pm 0.03$ \\
\hline 29 & Female & 54 & $29.34 \pm 0.27$ & Undetermined & $27.19 \pm 0.29$ \\
\hline 30 & Female & 32 & $25.52 \pm 0.26$ & $28.45 \pm 0.10$ & $23.56 \pm 0.28$ \\
\hline 31 & Female & 80 & $24.81 \pm 0.15$ & Undetermined & $24.15 \pm 0.09$ \\
\hline 32 & Female & 53 & $26.41 \pm 0.19$ & Undetermined & $27.45 \pm 0.31$ \\
\hline 33 & Female & 85 & $23.28 \pm 0.10$ & Undetermined & $21.67 \pm 0.10$ \\
\hline 34 & Female & 43 & $28.76 \pm 0.30$ & Undetermined & $28.29 \pm 0.15$ \\
\hline 35 & Female & 60 & $24.54 \pm 0.28$ & $27.62 \pm 0.26$ & $22.59 \pm 0.13$ \\
\hline 36 & Female & 61 & $29.60 \pm 0.36$ & Undetermined & $29.33 \pm 0.29$ \\
\hline 37 & Female & 77 & $27.57 \pm 0.31$ & Undetermined & $26.47 \pm 0.15$ \\
\hline 38 & Female & 56 & $29.82 \pm 0.03$ & Undetermined & $29.21 \pm 0.04$ \\
\hline 39 & Female & 59 & $24.70 \pm 0.18$ & $31.44 \pm 0.18$ & $22.49 \pm 0.35$ \\
\hline 40 & Female & 32 & $22.80 \pm 0.16$ & $28.41 \pm 0.15$ & $21.59 \pm 0.11$ \\
\hline 41 & Female & 68 & $26.29 \pm 0.18$ & $34.51 \pm 0.34$ & $25.67 \pm 0.10$ \\
\hline 42 & Female & 64 & $27.37 \pm 0.48$ & Undetermined & $26.29 \pm 0.15$ \\
\hline 43 & Female & 60 & $27.95 \pm 0.02$ & Undetermined & $26.59 \pm 0.13$ \\
\hline 44 & Female & 58 & $30.49 \pm 0.17$ & Undetermined & $30.39 \pm 0.23$ \\
\hline 45 & Female & 78 & $26.27 \pm 0.42$ & Undetermined & $24.74 \pm 0.55$ \\
\hline 46 & Female & 60 & $27.44 \pm 0.34$ & Undetermined & $27.24 \pm 0.22$ \\
\hline 47 & Female & 58 & $29.74 \pm 0.16$ & Undetermined & $29.38 \pm 0.24$ \\
\hline 48 & Female & 42 & $22.42 \pm 0.25$ & $31.48 \pm 0.39$ & $21.32 \pm 0.22$ \\
\hline 49 & Female & 25 & $23.71 \pm 0.20$ & Undetermined & $23.45 \pm 0.22$ \\
\hline 50 & Female & 57 & $23.61 \pm 0.44$ & Undetermined & $25.42 \pm 0.52$ \\
\hline
\end{tabular}




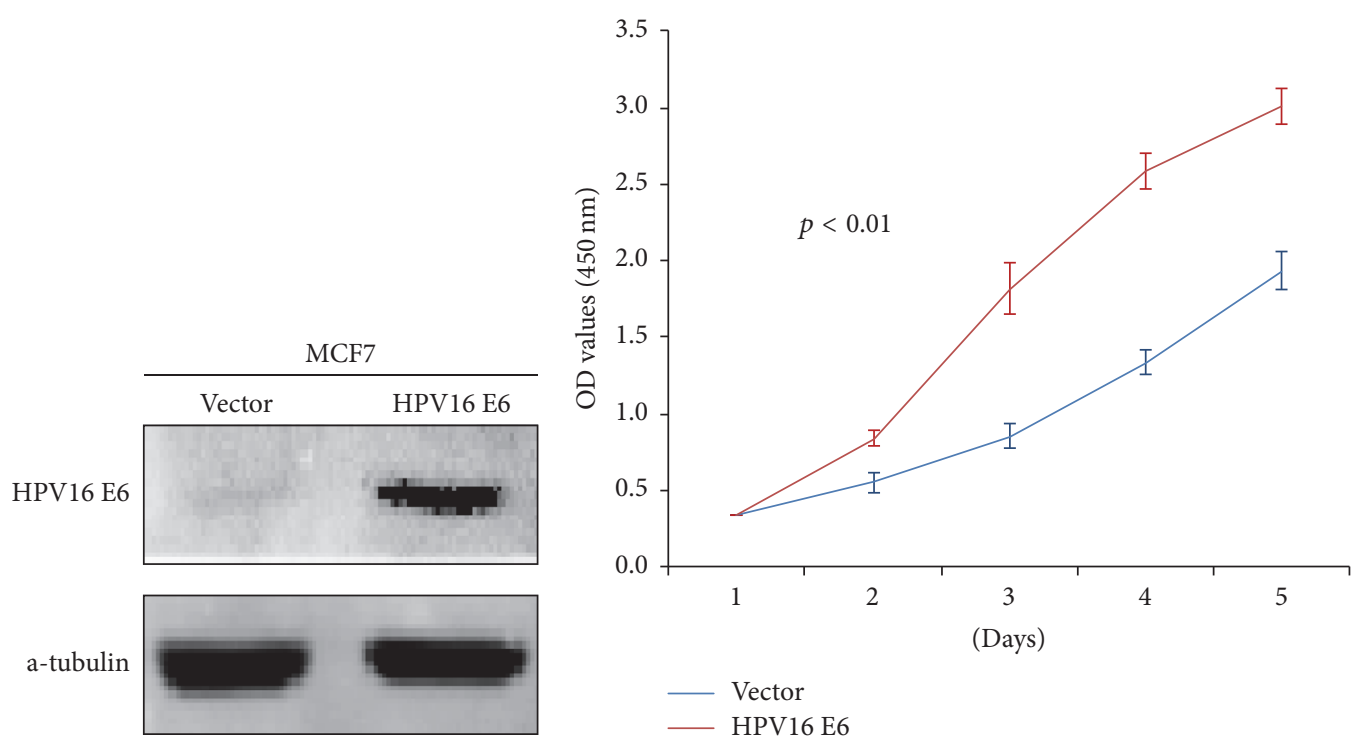

(a)

(b)
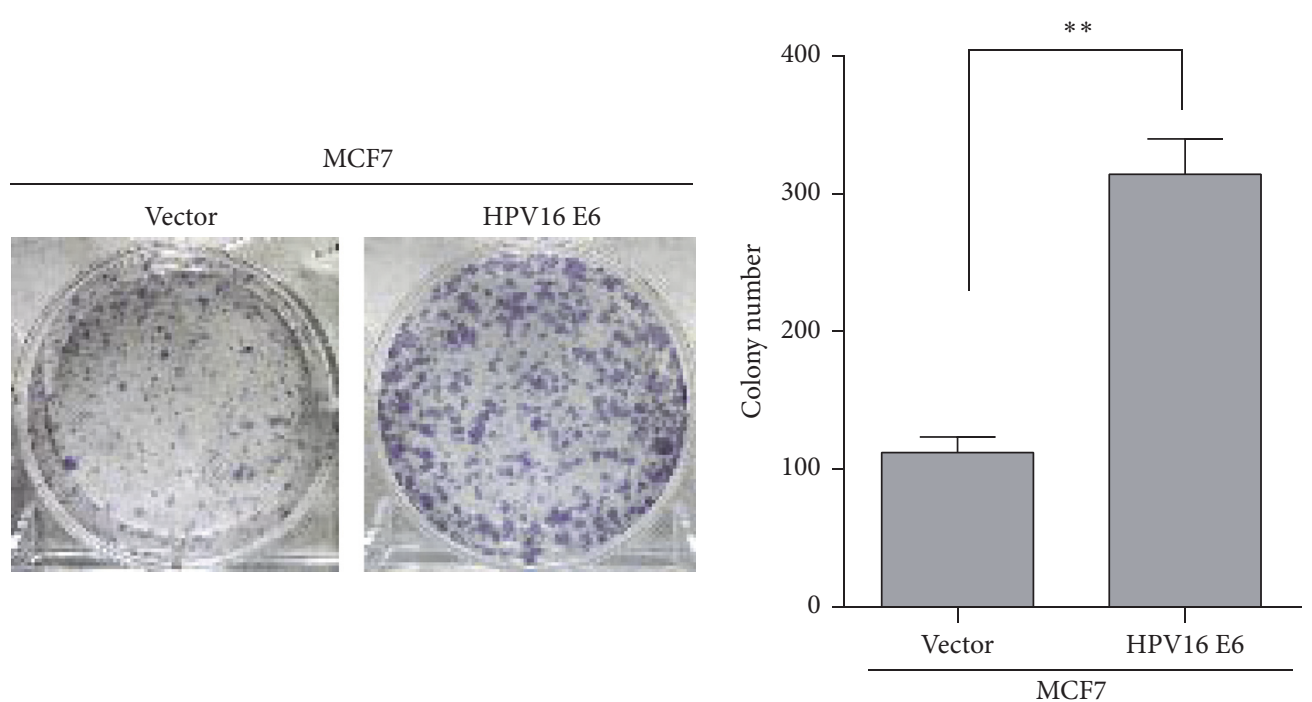

(c)
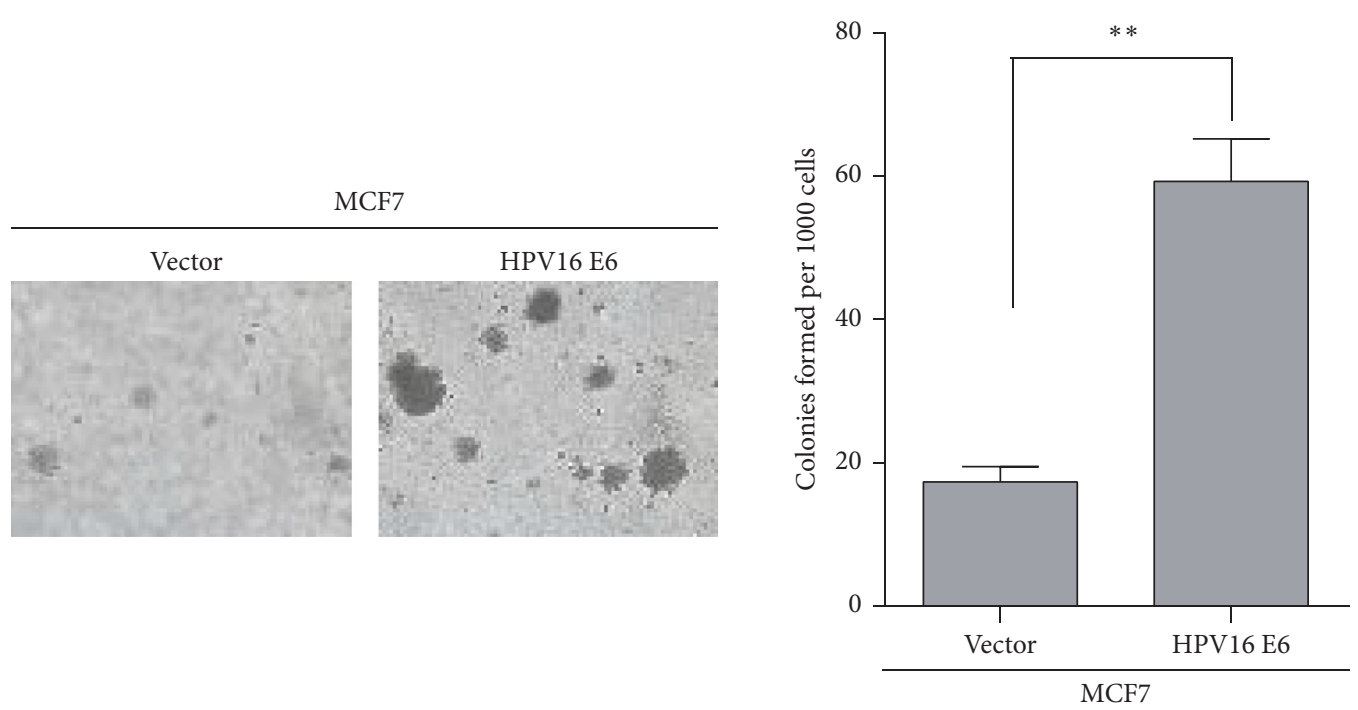

(d)

Figure 1: Continued. 

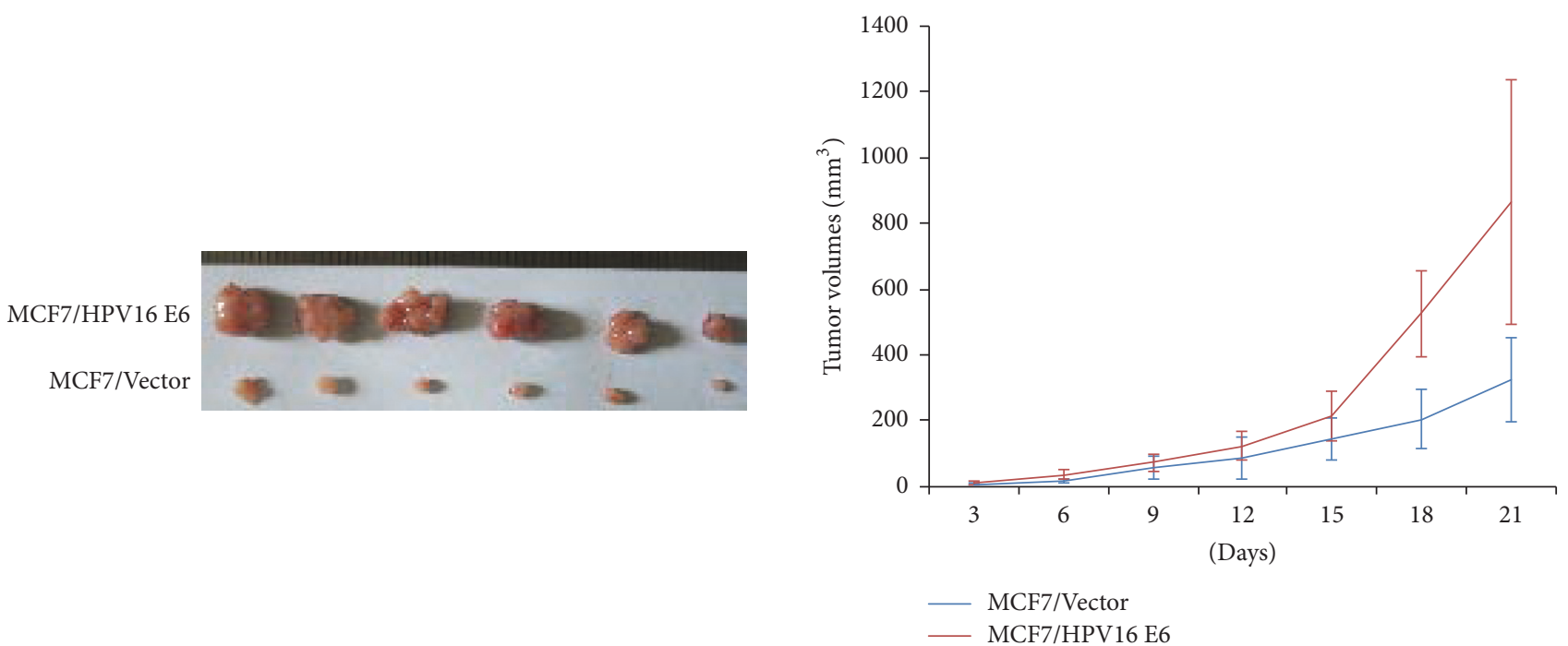

(e)
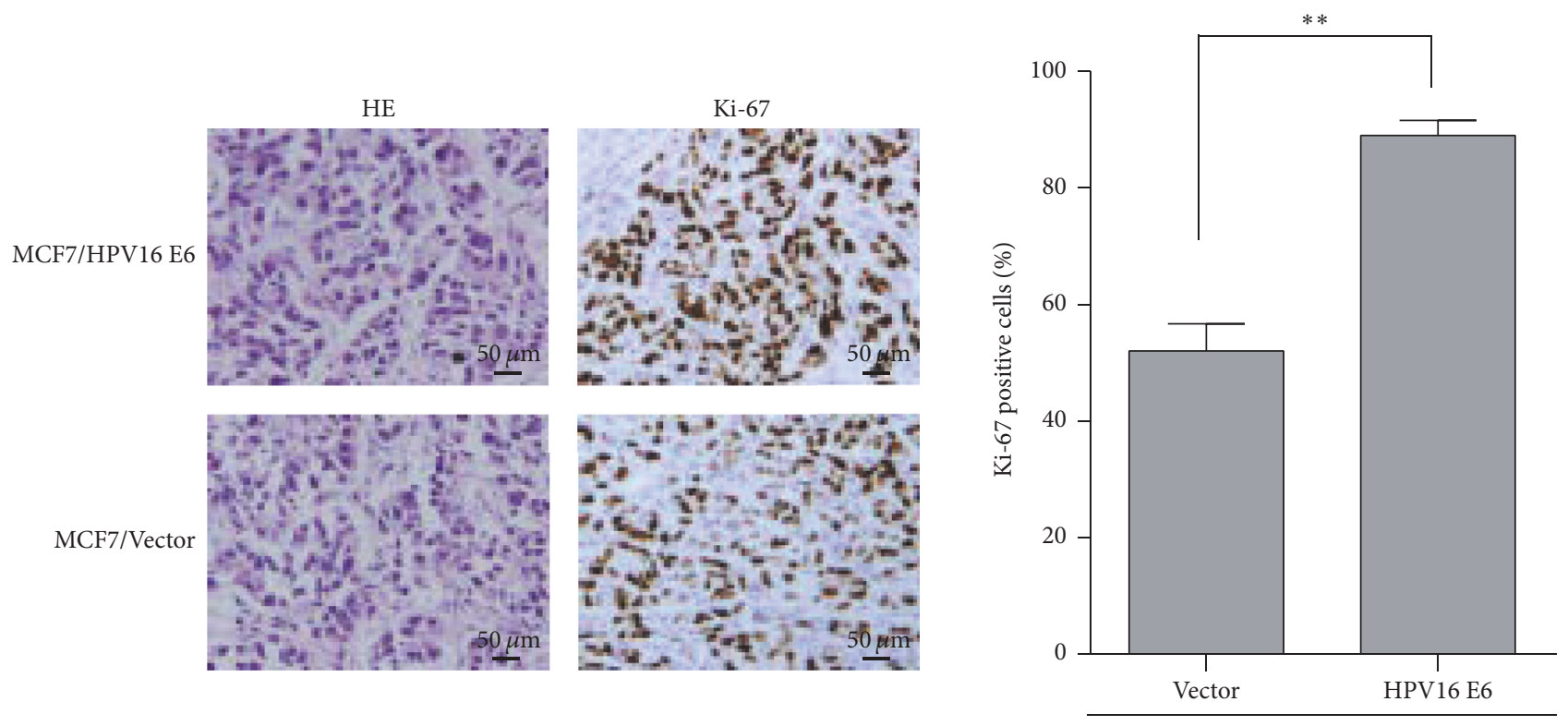

MCF7

(f)

FIGURE 1: HPV16 E6 promotes the proliferation of breast cancer. (a) The expression of HPV16 E6 in MCF-7/HPV16 E6 and MCF-7/Vector by Western blot. (b)-(d) The proliferative ability of the indicated cells detected by MTT assays, colony formation assays, and soft agar assays. Only cell colonies containing more than 50 cells were counted. Error bars represent mean \pm SD from 3 independent experiments. ${ }^{* *} p<0.01$. (e) MCF-7/HPV16 E6 and MCF-7/Vector cells were injected into the hind limbs of nude mice $(n=6)$. Tumor volumes were measured on the indicated days. The tumor volume data were presented as the mean \pm SD. (f) Histopathological analyses of xenograft tumor. The tumor sections were stained with H\&E or subjected to IHC staining using an antibody against Ki-67. Error bars represent mean \pm SD from three independent experiments. ${ }^{* *} p<0.01$.

samples (Figure 3(a)) (Table 2). In addition, HPV16 E6 and COX-2 protein were detected in these 50 cases of paraffinembedded breast invasive ductal carcinoma samples by IHC (Figure 3(b)). The HPV16 E6 protein was expressed in 14 cases, which was in accordance with the qPCR results. The Spearman correlation analysis showed that there was positive correlation between HPV16 E6 and COX-2 expression in breast invasive ductal carcinoma (Table 3 ).
3.5. HPV16 E6 Upregulates COX2 Expression by Activating $N F-\kappa B$ Signaling Pathway. The activity of NF- $\kappa$ B signaling pathway was found increased significantly by the expression of HPV16 E6 in MCF-7/HPV16 E6 than that in MCF7/Vector cells (Figure 4(a)). And the overexpression of COX2 induced by the expression of HPV16 E6 in MCF-7/HPV16 E6 cells could be suppressed after being treated with PDTC (Figure 4(b)). 


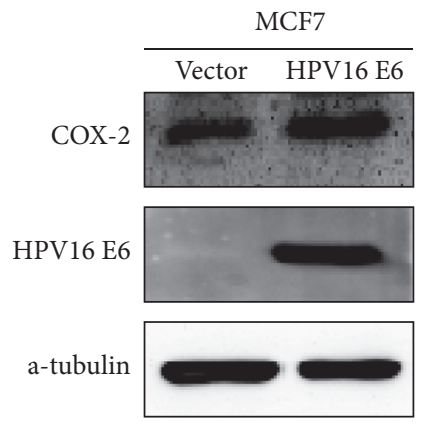

(a)

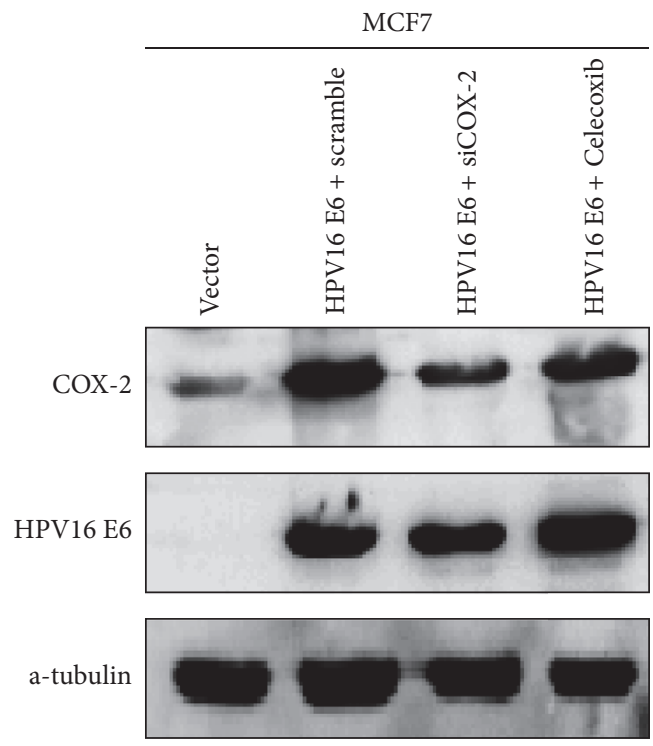

(b)

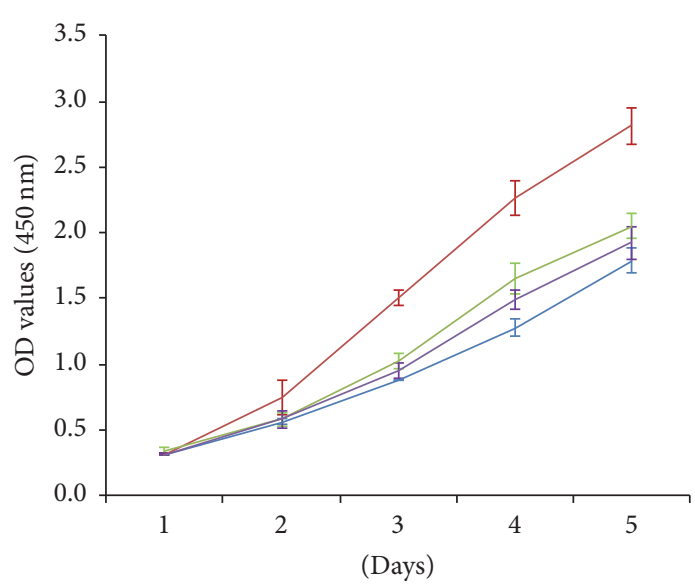

- Vector — HPV16 E6 + scramble — HPV16 E6 + Celecoxib

(c)
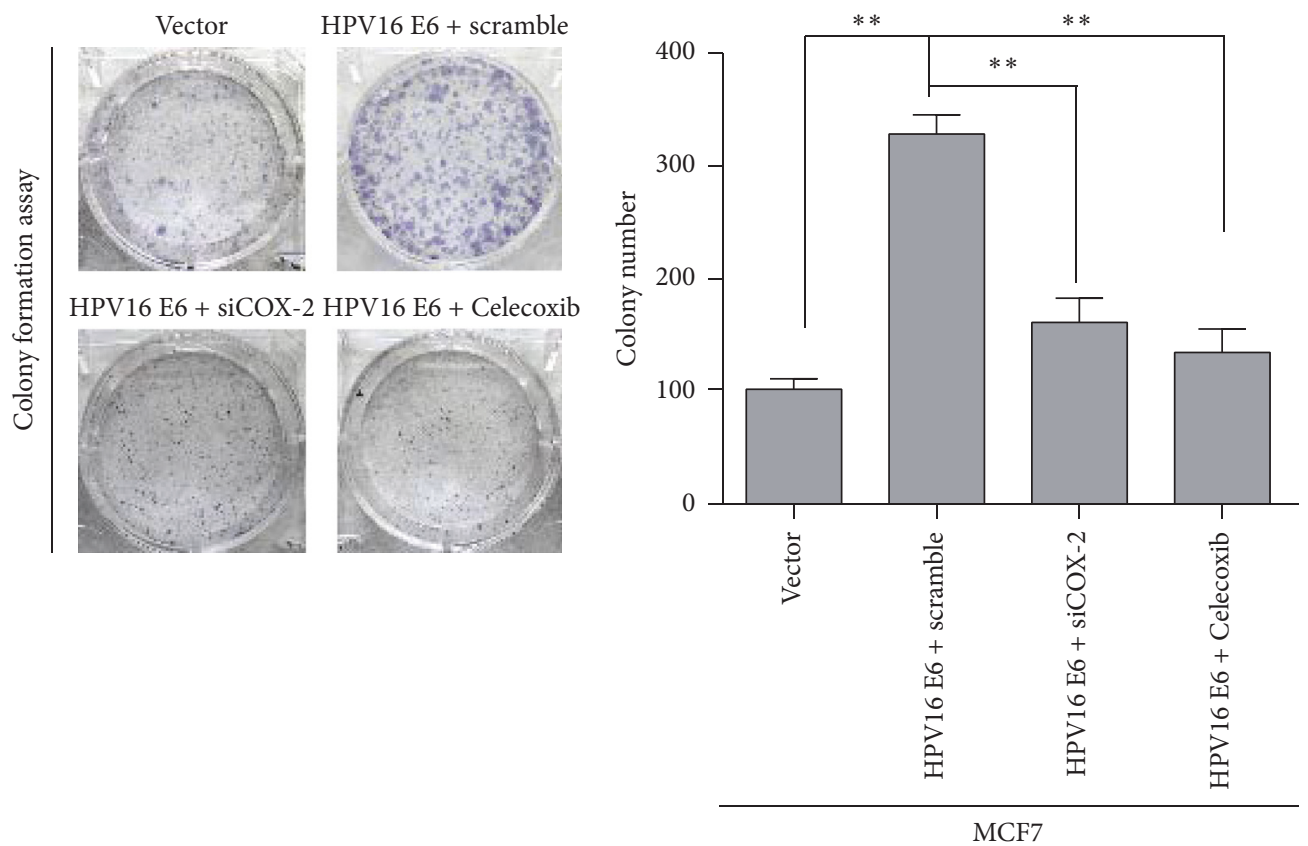

(d)

FIgURE 2: Continued. 

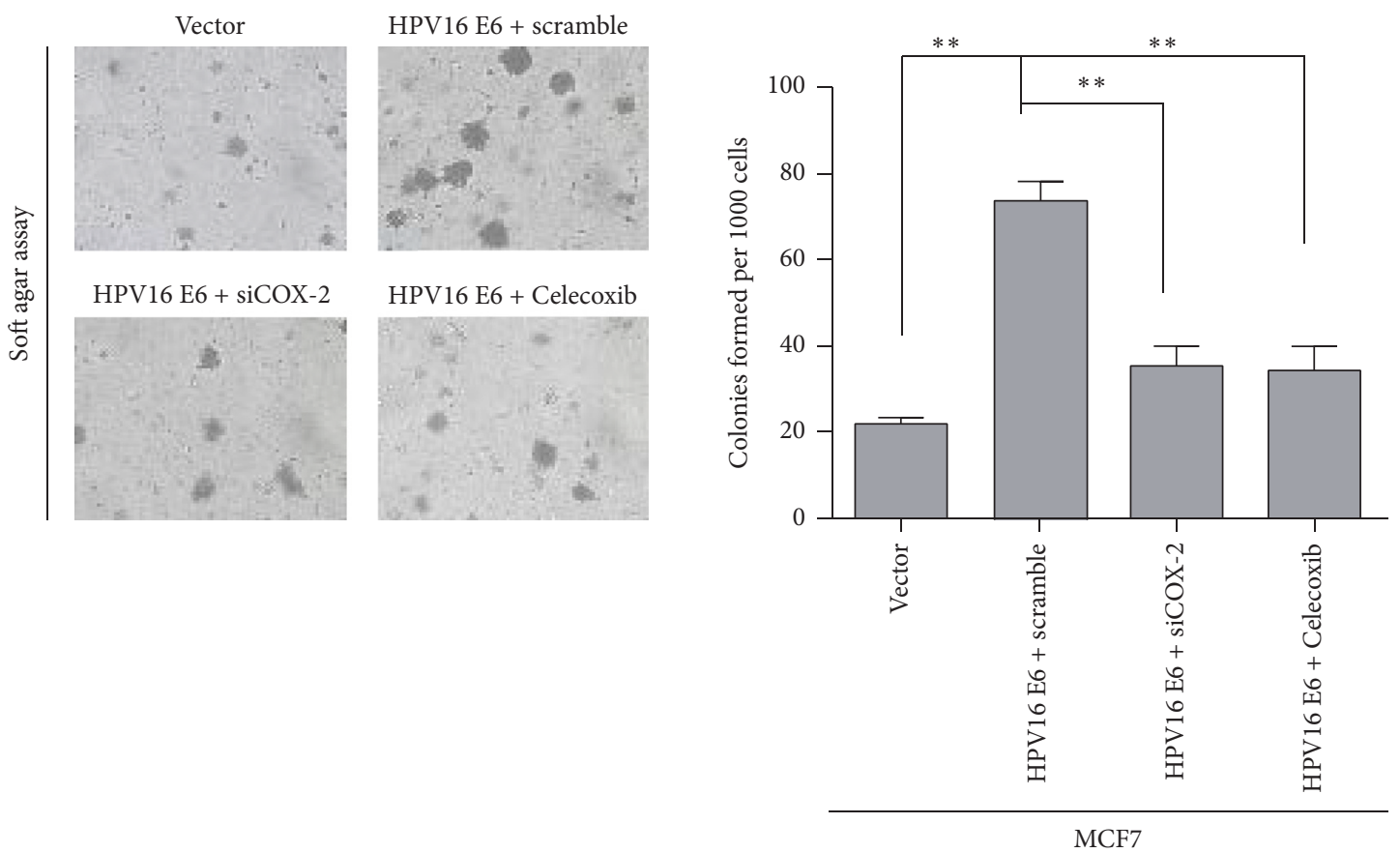

(e)

FIGURE 2: HPV16 E6 promotes the proliferation of breast cancer by upregulating COX-2 expression. (a) The expression of HPV16 E6 and COX-2 expression in MCF-7/HPV16 E6 and MCF-7/Vector cells. (b) The construction of cells with HPV16 E6 expression and COX-2 suppression which induced by siCOX-2 and Celecoxib. (c)-(e) The proliferative ability of the indicated cells detected by MTT assays, colony formation assays, and soft agar assays. Only cell colonies containing more than 50 cells were counted. Error bars represent mean \pm SD from 3 independent experiments. ${ }^{* *} p<0.01$.

TABLE 3: Correlation between HPV16 E6 and COX-2 expression in invasive ductal breast cancer tissues by IHC.

\begin{tabular}{lcccc}
\hline HPV16 E6 expression & COX-2 expression & Low & $r$ value \\
\hline Positive & High & 2 & 0.327 \\
Negative & 12 & 18 & 0.020 \\
\hline
\end{tabular}

\section{Discussion}

It has been reported that HPV could induce a range of benign and malignant lesions, especially high-risk HPV types such as HPV16 and HPV18, which are closely correlated with the occurrence of some malignant lesions. For example, both epidemiologic and experimental evidence had demonstrated that some HR-HPVs could induce cervical cancer. HPV16 could encode E6 oncoprotein, which had effects on the carcinogenesis, proliferation, invasion, and metastasis. However, the association of HPV16 with breast cancer varies widely. It was first reported that HPV16 could immortalize normal human mammary epithelial cells and reduce their growth factor requirements [19]. Up to now, HPV16 has been repeatedly detected in 0 to $86 \%$ of breast cancer which indicated an inconsistent association of HPV16 with breast cancer. But the recent meta-analysis does suggest an increased risk of breast cancer by HPV infection [20].

In this study, we detected the HPV16 E6 DNA in breast invasive ductal carcinoma samples and found that it could be detected in $28 \%$ of them. That is to say, HPV16 E6 might be an important factor to breast cancer in the north of China. Also we found that the infection of HPV16 E6 could increase the proliferation of breast cancer. It is important to explore molecular targets for gene therapy of HPV16 E6-associated breast cancer. Although there had been some efficacious vaccines for the prevention of HPV infection, they do not work for those already infected with HPV. Therefore, further studies are necessary to develop better therapeutic options for the treatment of HPV infection. In our study, we found that the expression of COX-2 in HPV16 E6 positive breast invasive ductal carcinoma cases was much higher than that in HPV16 E6 negative ones. This result indicated that the expression of COX-2 could be upregulated by the expression of HPV16 E6, which agrees with the previous studies in other cancers $[21,22]$. COX-2 is the key rate-limiting enzyme in PGE2 synthesis and plays critical roles in tumor associated immune dysfunction and cancer progression $[23,24]$. We inferred that COX-2 might be an important target for HPV16 E6-associated breast cancer. 


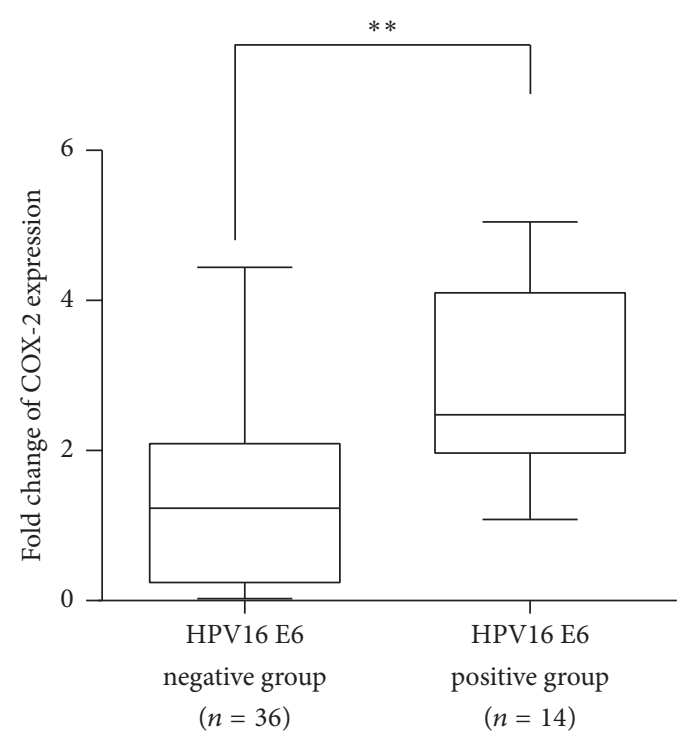

(a)

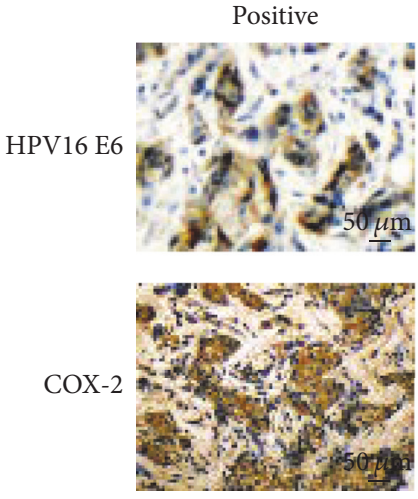

High

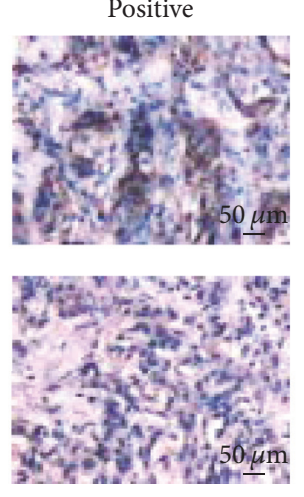

Low

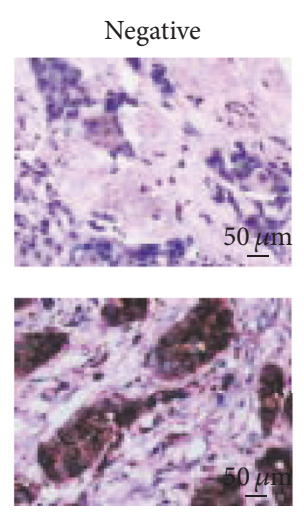

High
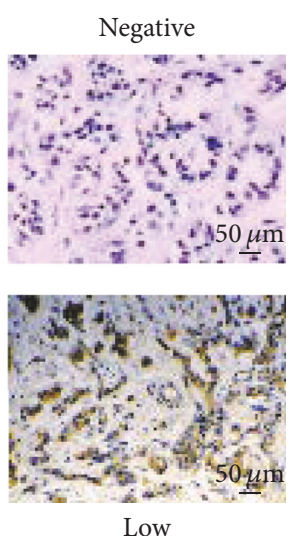

(b)

Figure 3: HPV16 E6 expression positively correlates with COX-2 expression in breast cancer. (a) The expression of COX-2 DNA in HPV16 E6 positive and negative invasive ductal breast cancer samples by qPCR analysis $\left(2^{-\Delta \Delta C T}\right) .{ }^{* *} p<0.01$. (b) The representative images of HPV16 E6 and COX-2 expression in invasive ductal breast carcinoma tissues by IHC.

In the following study, we found that the suppression of COX-2 significantly inhibited the proliferation of MCF7/HPV16 E6 cells. The results demonstrated that the effects of HPV16 E6 in promoting breast cancer proliferation were achieved by the upregulation of COX-2. It has been reported that COX-2 plays important roles in the carcinogenesis and development of many tumors including breast cancer [2527]. In the past few years, The animal experiments in vivo clearly indicate that high COX-2 expression is correlated to the genesis of mammary tumors that are sensitive to treatment with nonselective and selective COX-2 inhibitors. Recently, the combination of specific COX-2 inhibitors with conventional chemotherapy as a novel approach brings about some promising changes in the field of breast cancer treatment. Celecoxib is a selective COX2 inhibitor which has been used in the therapy of osteoarthritis and rheumatoid arthritis.
And now, it has been proven that Celecoxib could prevent carcinogenesis, delay cancer progression, and enhance the efficacy of conventional cancer therapies, such as chemotherapy and radiation therapy [28-31]. For example, nimotuzumab and Celecoxib exert synergistic antiproliferation effects in breast cancer [32]; adjuvant use of Celecoxib and lanreotide is beneficial for advanced hepatocellular carcinoma [33]. Therefore, more and more COX-2 inhibitors with improved anticancer activity are being developed [34-36]. Currently, there were no effective therapeutic methods for established HPV cancers [37]. Thus, it is urgent to develop effective therapeutic methods for treating HPV-induced cancers. It has been shown that Celecoxib-treated HPV16 +/- animals show reduced incidence of epidermal dysplasia than untreated mice [38]. Celecoxib was also reported to significantly decrease breast tumor volume in rats [39]. In conclusion, the 


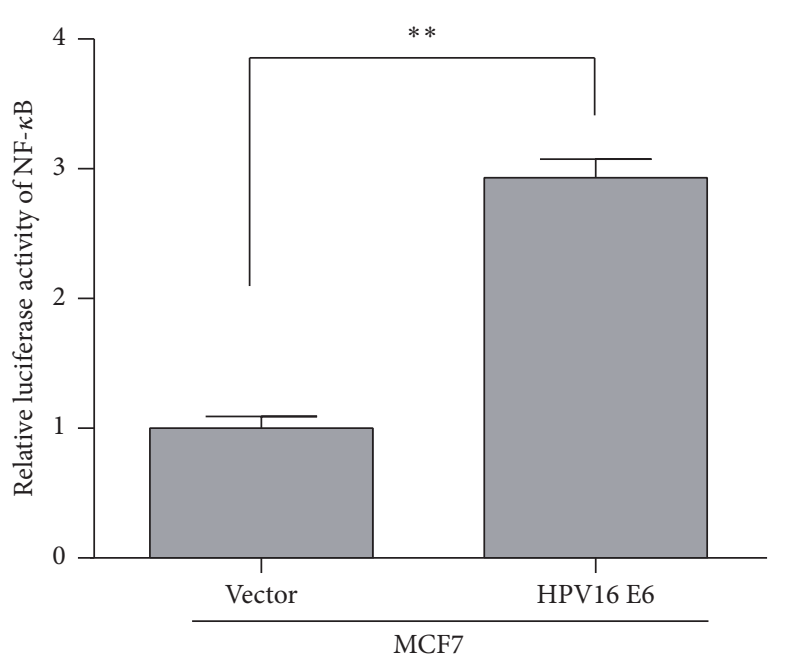

(a)
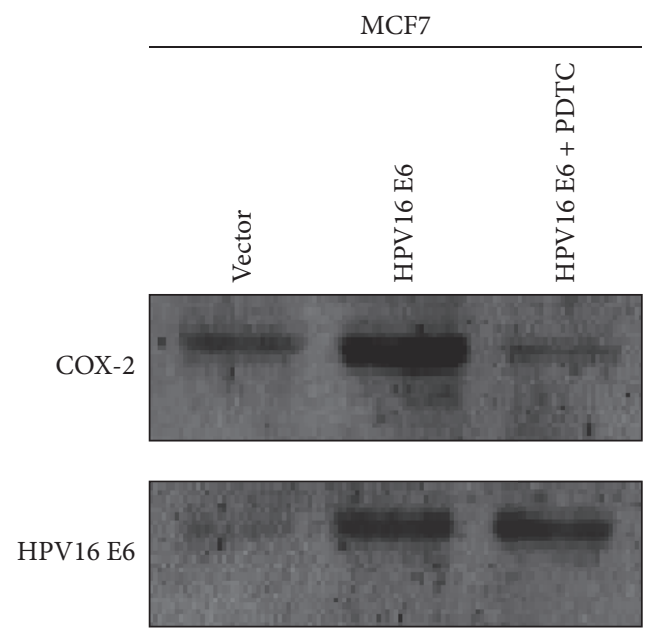

a-tubulin

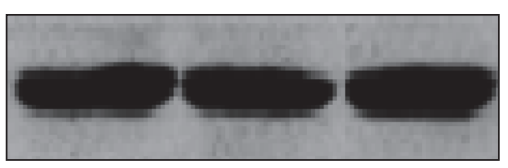

(b)

FIGURE 4: HPV16 E6 upregulates COX2 expression by activating NF- $\kappa B$ signaling pathway. (a) The luciferase activity of NF- $\kappa$ B in MCF-7 cells with the expression of HPV16 E6. ${ }^{* *} p<0.01$. (b) The expression of COX-2 protein in MCF-7 cells with different treatment.

use of Celecoxib might be an effective therapeutic method for $\mathrm{HPV}$-associated breast cancer.

$\mathrm{NF}-\kappa \mathrm{B}$, a pivotal transcriptional factor in cancer cells, participates in the tumorigenesis and progression by increasing proliferation, regulating angiogenesis and suppressing apoptosis. It has been reported that some E6/E7-regulated gene products are target genes of NF- $\kappa \mathrm{B}$, a dimeric transcription factor involved in the expression of proteins necessary for innate immunity, apoptosis, and cell proliferation. And accumulating studies have demonstrated that NF- $\kappa \mathrm{B}$ plays an important role in the regulation of COX-2 expression [40-42]. Therefore, we postulated whether the upregulation of COX-2 medicated by HPV16 E6 was achieved by the activation of NF- $\kappa$ B signaling pathway. Our study finally confirmed that HPV16 E6 can upregulate COX-2 expression by activating NF- $\kappa \mathrm{B}$ signaling pathway, which is in accordance with previous result [43].

Overall, our current study showed the presence of HPV16 E6 DNA in collected clinical biopsy sections from breast cancers (28\%), and the HPV16 E6 promoted the proliferation of breast cancer via activating NF- $\kappa$ B signaling pathway and upregulated the expression of COX-2. In addition, inhibition of COX-2 by siCOX-2 or Celecoxib attenuated the proliferation of breast cancer cells with HPV16 E6 expression. In conclusion, this study may provide a potent therapeutic target for HPV16 E6-associated breast cancer.

\section{Conflicts of Interest}

The authors declare that they have no conflicts of interest.

\section{Acknowledgments}

This work was supported by the Key Project of Henan Province Office of Education, China (14A310004).

\section{References}

[1] J. Ferlay, I. Soerjomataram, R. Dikshit et al., "Cancer incidence and mortality worldwide: sources, methods and major patterns in GLOBOCAN 2012," International Journal of Cancer, 2014.

[2] A. Jemal, F. Bray, M. M. Center, J. Ferlay, E. Ward, and D. Forman, "Global cancer statistics," CA: A Cancer Journal for Clinicians, vol. 61, no. 2, pp. 69-90, 2011.

[3] J. G. Brody, R. A. Rudel, K. B. Michels et al., "Environmental pollutants, diet, physical activity, body size, and breast cancer: Where do we stand in research to identify opportunities for prevention?" Cancer, vol. 109, no. 12, pp. 2627-2634, 2007.

[4] J. Kaiser, "Cholesterol forges link between obesity and breast cancer," Science, vol. 342, no. 6162, p. 1028, 2013.

[5] M. Gage, D. Wattendorf, and L. R. Henry, "Translational advances regarding hereditary breast cancer syndromes," Journal of Surgical Oncology, vol. 105, no. 5, pp. 444-451, 2012.

[6] T. Anothaisintawee, C. Wiratkapun, P. Lerdsitthichai et al., "Risk factors of breast cancer: a systematic review and meta-analysis," Asia-Pacific Journal of Public Health, vol. 25, no. 5, pp. 368-387, 2013.

[7] S. L. Glaser, A. J. Canchola, T. H. Keegan, C. A. Clarke, T. A. Longacre, and M. L. Gulley, "Variation in risk and outcomes of Epstein-Barr virus-associated breast cancer by epidemiologic characteristics and virus detection strategies: an exploratory study," Cancer Causes \& Control, vol. 28, no. 4, pp. 273-287, 2017. 
[8] H. Wu, C. Zhao, V. P. Adhikari, L. Lu et al., "The prevalence and clinicopathological features of breast cancer patients with hepatitis B virusinfection in China," Oncotarget, 2017.

[9] N. E. Ilahi, S. Anwar, M. Noreen, S. N. Hashmi, and S. Murad, "Detection of human papillomavirus-16 DNA in archived clinical samples of breast and lung cancer patients from North Pakistan," Journal of Cancer Research and Clinical Oncology, vol. 142, no. 12, pp. 2497-2502, 2016.

[10] Y. Omura, M. K. Jones, A. Nihrane, H. Duvvi, Y. Shimotsuura, and M. Ohki, "More than $97 \%$ of human papilloma virus type 16 (hpv-16) was found with chrysotile asbestos \& relatively smooth round tumor outline, and less than 3\% was found with hpv-18 and tremolite asbestos \& irregular sawtooth-like zigzag outline in breast cancer tissues in over 500 mammograms of female patients: their implications in diagnosis, treatment, and prevention of breast cancer," Acupuncture and ElectroTherapeutics Research, vol. 38, no. 3-4, pp. 211-230, 2013.

[11] W. Yin, D. Duluc, H. Joo, and et al, "Dendritic cell targeting vaccine for HPV-associated cancer," Cancer Cell Microenviron, vol. 3, no. 4, 1482 pages, 2016.

[12] K. K. Wu, "Cyclooxygenase 2 induction: molecular mechanism and pathophysiologic roles," Journal of Laboratory and Clinical Medicine, vol. 128, no. 3, pp. 242-245, 1996.

[13] R. E. Harris, B. C. Casto, and Z. M. Harris, "Cyclooxygenase2 and the inflammogenesis of breast cancer," World Journal of Clinical Oncology, vol. 5, no. 4, pp. 677-692, 2014.

[14] L. Wang, S. Gao, W. Jiang et al., "Antioxidative dietary compounds modulate gene expression associated with apoptosis, DNA repair, inhibition of cell proliferation and migration," International Journal of Molecular Sciences, vol. 15, no. 9, pp. 16226-16245, 2014.

[15] Q. Zhao, J. Guo, G. Wang, Y. Chu, and X. Hu, "Suppression of immune regulatory cells with combined therapy of celecoxib and sunitinib in renal cell carcinoma," Oncotarget, vol. 8, no. 1, pp. 1668-1677, 2017.

[16] S. Tury, V. Becette, F. Assayag et al., "Combination of COX-2 expression and PIK3CA mutation as prognostic and predictive markers for celecoxib treatment in breast cancer," Oncotarget, vol. 7, no. 51, pp. 85124-85141, 2016.

[17] B. Riva, M. De Dominici, I. Gnemmi et al., "Celecoxib inhibits proliferation and survival of chronic myelogeous leukemia (CML) cells via AMPK-dependent regulation of $\beta$-catenin and mTORC1/2," Oncotarget, vol. 7, no. 49, pp. 81555-81570, 2016.

[18] K. Friedrichs, S. Gluba, H. Eidtmann, and W. Jonat, "Overexpression of p53 and prognosis in breast cancer," Cancer, vol. 72, no. 12, pp. 3641-3647, 1993.

[19] V. Band, S. Dalal, L. Delmolino, and E. J. Androphy, "Enhanced degradation of p53 protein in HPV-6 and BPV-1 E6immortalized human mammary epithelial cells," $E M B O$ Journal, vol. 12, no. 5, pp. 1847-1852, 1993.

[20] J.-M. Bae and E. H. Kim, "Human papillomavirus infection and risk of breast cancer: a meta-analysis of case-control studies," Infectious Agents and Cancer, vol. 11, 14 pages, 2016.

[21] R. Wu, A. L. Abramson, M. J. Shikowitz, A. J. Dannenberg, and B. M. Steinberg, "Epidermal growth factor-induced cyclooxygenase-2 expression is mediated through phosphatidylinositol3 kinase, not mitogen-activated protein/extracellular signalregulated kinase kinase, in recurrent respiratory papillomas," Clinical Cancer Research, vol. 11, no. 17, pp. 6155-6161, 2005.

[22] K. Subbaramaiah and A. J. Dannenberg, "Cyclooxygenase2 transcription is regulated by human papillomavirus 16 E6 and E7 oncoproteins: evidence of a corepressor/coactivator exchange," Cancer Research, vol. 67, no. 8, pp. 3976-3985, 2007.

[23] N. Obermajer, R. Muthuswamy, J. Lesnock, R. P. Edwards, and P. Kalinski, "Positive feedback between PGE2 and COX2 redirects the differentiation of human dendritic cells toward stable myeloid-derived suppressor cells," Blood, vol. 118, no. 20, pp. 5498-5505, 2011.

[24] P. Sinha, V. K. Clements, A. M. Fulton, and S. OstrandRosenberg, "Prostaglandin E2 promotes tumor progression by inducing myeloid-derived suppressor cells," Cancer Research, vol. 67, no. 9, pp. 4507-4513, 2007.

[25] N. Campillo, M. Torres, A. Vilaseca et al., "Role of cyclooxygenase-2 on intermittent hypoxia-induced lung tumor malignancy in a mouse model of sleep apnea," Scientific Reports, vol. 7, p. 44693, 2017.

[26] H. Hsu, M. Chen, C. H. Day et al., "Thymoquinone suppresses migration of LoVo human colon cancer cells by reducing prostaglandin E2 induced COX-2 activation," World Journal of Gastroenterology, vol. 23, no. 7, p. 1171, 2017.

[27] S. Shirali, A. Barari, SA. Hosseini et al., "Effects of six weeks endurance training and aloe vera supplementation on COX2 and VEGF levels in mice with breast cancer," Asian Pacific Journal of Cancer Prevention, vol. 18, no. 1, pp. 31-36, 2017.

[28] J. Sun, N. Liu, H. Zhuang, L. Zhao, Z. Yuan, and P. Wang, "Celecoxib-erlotinib combination treatment enhances radiosensitivity in A549 human lung cancer cell," Cancer Biomarkers, vol. 19, no. 1, pp. 45-50, 2017.

[29] W. L. Pridgen, C. Duffy, J. F. Gendreau, and R. M. Gendreau, "A famciclovir + celecoxib combination treatment is safe and efficacious in the treatment of fibromyalgia," Journal of Pain Research, vol. Volume 10, pp. 451-460, 2017.

[30] B. Liu, S. Yan, L. Qu, and J. Zhu, "Celecoxib enhances anticancer effect of cisplatin and induces anoikis in osteosarcoma via PI3K/Akt pathway," Cancer Cell International, vol. 17, no. 1, 2017.

[31] Q. Zhao, J. Guo, G. Wang, Y. Chu, and X. Hu, "Suppression of immune regulatory cells with combined therapy of celecoxib and sunitinib in renal cell carcinoma," Oncotarget, vol. 8, no. 1, pp. 1668-1677, 2017.

[32] Y.-X. Wang, J.-X. Gao, X.-Y. Wang, L. Zhang, and C.-M. Liu, "Antiproliferative effects of selective cyclooxygenase-2 inhibitor modulated by nimotuzumab in estrogen-dependent breast cancer cells," Tumor Biology, vol. 33, no. 4, pp. 957-966, 2012.

[33] H. Tong, B. Wei, S. Chen et al., "Adjuvant celecoxib and lanreotide following transarterial chemoembolisation for unresectable hepatocellular carcinoma: a randomized pilot study," Oncotarget, 2017.

[34] R. Ghodsi, E. Azizi, and A. Zarghi, "Synthesis and biological evaluation of 4-(imidazolylmethyl)-2-(4-methylsulfonyl phenyl)-quinoline derivatives as selective COX-2 Inhibitors and in-vitro anti-breast cancer agents," Iranian Journal of Pharmaceutical Research, vol. 15, no. 1, pp. 169-177, 2016.

[35] W. Akhtar, G. Verma, M. F. Khan et al., "Synthesis of hybrids of dihydropyrimidine and pyridazinone as potential anti-breast cancer agents," Mini-Reviews in Medicinal Chemistry, 2017.

[36] C. Bocca, F. Bozzo, A. Bassignana, and A. Miglietta, "Antiproliferative effects of COX-2 inhibitor celecoxib on human breast cancer cell lines," Molecular and Cellular Biochemistry, vol. 350, no. 1-2, pp. 59-70, 2011.

[37] A. Yang, J. Jeang, K. Cheng et al., "Current state in the development of candidate therapeutic HPV vaccines," Expert Review of Vaccines, vol. 15, no. 8, pp. 989-1007, 2016. 
[38] D. A. Costa RMG, R. Araújo, J. M. O. Santos et al., "Regulation of miRNA-146a and miRNA-150 Levels by Celecoxib in Premalignant Lesions of K14-HPV16 Mice," Anticancer Research, vol. 37, no. 6, pp. 2913-2918, 2017.

[39] G. A. Alshafie, H. M. Abou-Issa, K. Seibert et al., "Chemotherapeutic evaluation of celecoxib, a cyclooxygenase-2 inhibitor, in a rat mammarytumor model," Oncology Reports, vol. 7, no. 6, pp. 1377-1381, 2000.

[40] C.-C. Lin, C.-M. Chan, Y.-P. Huang, S.-H. Hsu, C.-L. Huang, and S.-J. Tsai, "Methylglyoxal activates NF- $\kappa$ B nuclear translocation and induces COX-2 expression via a p38-dependent pathway in synovial cells," Life Sciences, vol. 149, pp. 25-33, 2016.

[41] S. Norouzi, M. Norouzi, M. Amini et al., "Two COX-2 inhibitors induce apoptosis in human erythroleukemia K562cells by modulating NF- $\kappa \mathrm{B}$ and FHC pathways," DARU, Journal of Pharmaceutical Sciences, vol. 24, no. 1, article no. 1, 2016.

[42] Y. Yu, X. Li, L. Qu et al., "DXXK exerts anti-inflammatory effects by inhibiting the lipopolysaccharide-induced NF- $\kappa \mathrm{B} / \mathrm{COX}-2$ signalling pathway and the expression of inflammatory mediators," Journal of Ethnopharmacology, vol. 178, pp. 199-208, 2016.

[43] M. Xu, R. A. Katzenellenbogen, C. Grandori, and D. A. Galloway, "NFX1 plays a role in human papillomavirus type 16 E6 activation of NFאB activity," Journal of Virology, vol. 84, no. 21, pp. 11461-11469, 2010. 


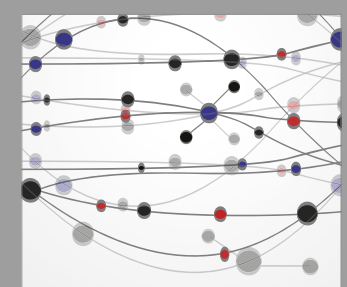

The Scientific World Journal
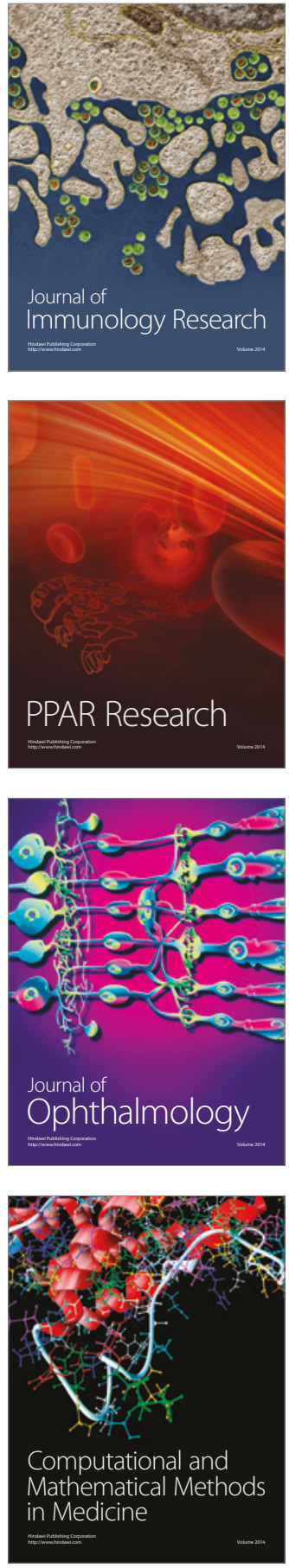

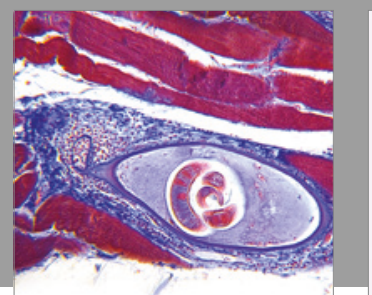

Gastroenterology Research and Practice
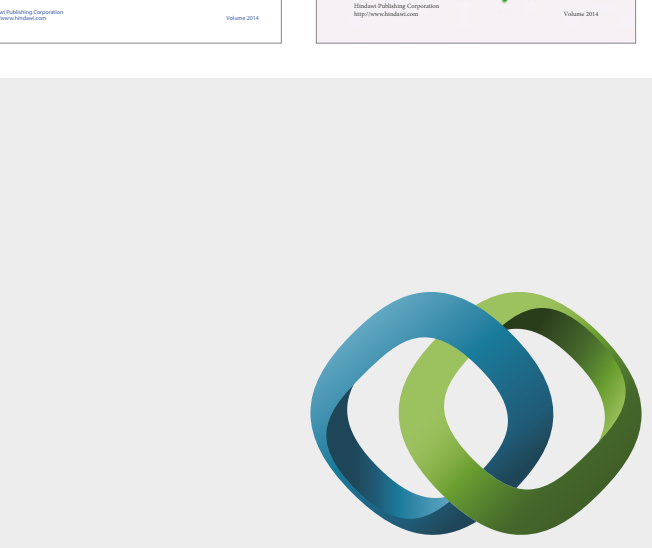

\section{Hindawi}

Submit your manuscripts at

https://www.hindawi.com
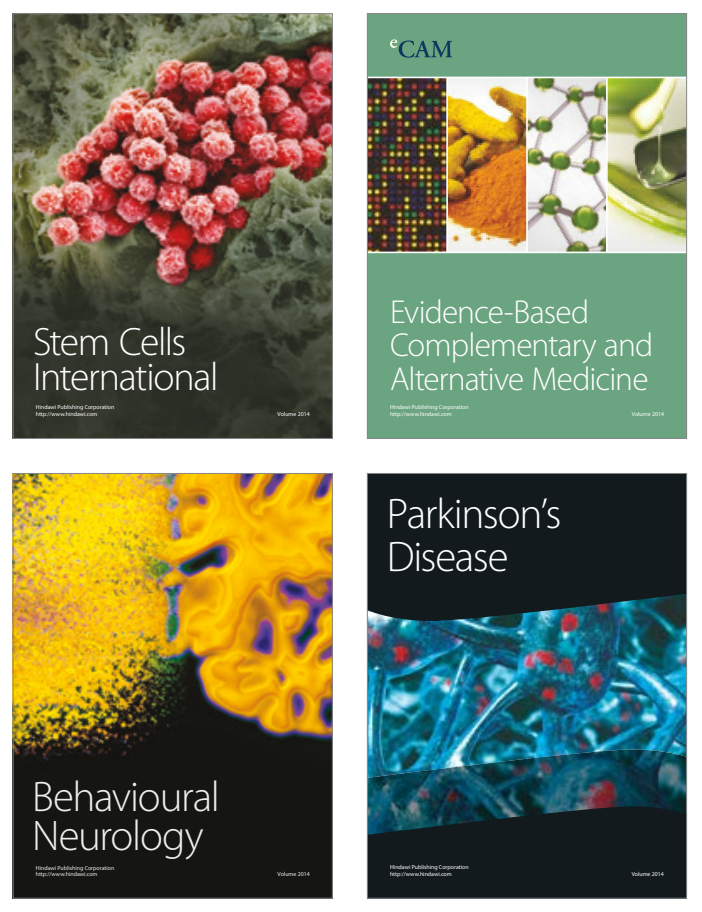
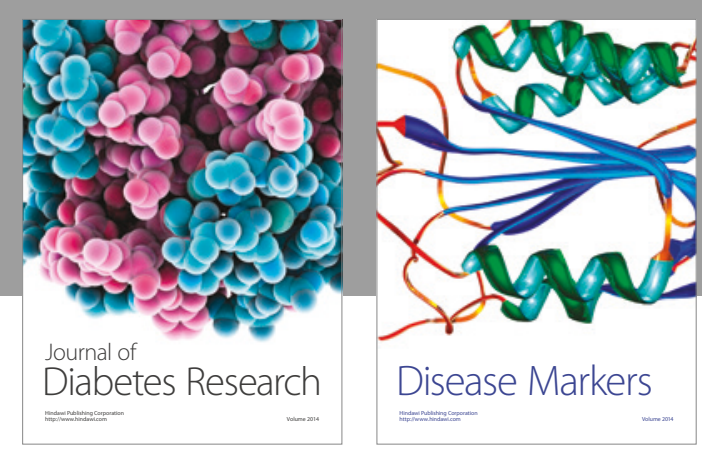

Disease Markers
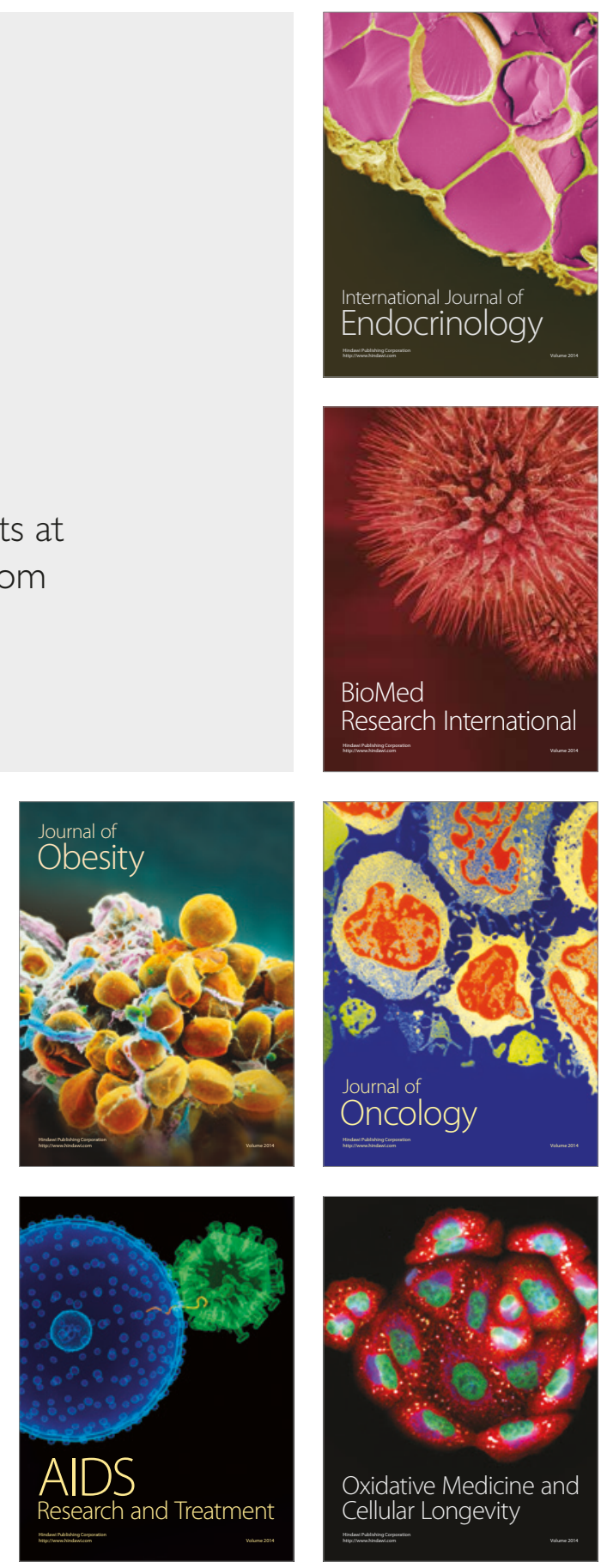